\title{
A comparative study of PSI and Curb-65 scoring systems in predicting ICU admissions and mortality in cases of community-acquired pneumonia
}

\author{
Patil P. ${ }^{1}$, Tyagi A. ${ }^{2 *}$, Waghmare M. $^{3}$, Srivastava A. ${ }^{4}$, Waran M. ${ }^{5}$ \\ DOI: https://doi.org/10.17511/ijmrr.2020.i03.04 \\ 1 Prashant Patil, Resident, Department of Medicine, DVVPF's Medical College, Ahmednagar, Maharashtra, India.

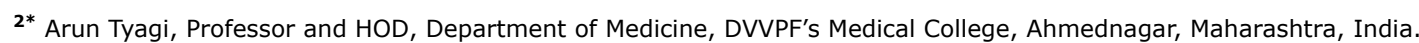 \\ 3 Manoj Waghmare, Assistant Professor, Department of Pulmonology, DVVPF's Medical College, Ahmednagar, Maharashtra, India. \\ ${ }^{4}$ A.K. Srivastava, Professor, Department of Medicine, DVVPF's Medical College, Ahmednagar, Maharashtra, India. \\ $\mathbf{5}$ Marcia Waran, Professor, Department of Medicine, DVVPF's Medical College, Ahmednagar, Maharashtra, India.
}

Background: Community-acquired pneumonia (CAP) is a leading cause of morbidity and mortality worldwide. Despite advanced diagnostic modalities and treatment options, CAP is the fourth leading cause of death in developing countries.Several severity scores have been proposed to guide initial decision making on hospitalization and to predict the outcome. Pneumonia Severity Index (PSI) and CURB 65 are the two most widely used scoring systems to prognosticate pneumonia. Aim: To compare the efficacy of PSI and CURB 65 scoring systems inprognosticating the ICU admission and outcome in cases of CAP. Methodology: This wasan observational study conducted at a tertiary care hospital in western Maharashtra. A hundred patients of CAP fulfilling the inclusion criteria were enrolled in the study, classified as per CURB 65 and PSI system and their outcome compared. Result: The study subjects comprised of 100 patients (64 men and 36 women) of CAP. Twenty-four patients needed ICU admission. In both PSI and CURB-65 risk scoring systems, the need for intensive care unit (ICU) admission and mortality rates increased progressively with increasing scores.PSI class $\geq$ IV and CURB $65 \geq$ III had $77.52 \%$ and $40.24 \%$ sensitivity and $88.46 \%$ and $69.48 \%$ specificity respectively in predicting ICU admissions. The PSI class $\geq$ IV had more sensitivity and specificity in predicting ICU admission than CURB-65. Conclusion: The PSI is better in predicting the need for ICU admission and CURB 65 is a better predictor of mortality in cases of community-acquired pneumonia.

Keywords: Community-acquired pneumonia, Curb-65, Pneumonia severity index

Corresponding Author

Arun Tyagi, Professor and HOD, Department of Medicine, DVVPF's Medical College, Ahmednagar, Maharashtra, India.

Email: aruntyagidr@gmail.com
How to Cite this Article

Patil P, Tyagi A, Waghmare M, Srivastava AK, Waran M. A comparative study of PSI and Curb-65 scoring systems in predicting ICU admissions and mortality in cases of community-acquired pneumonia. Int J Med Res Rev. 2020;8(3):240-246. Available From https://ijmrr.medresearch.in/index.php/ijmrr/article/ view/1189
To Browse

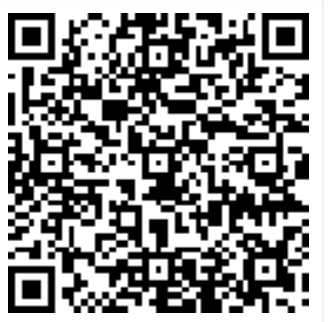




\section{Introduction}

Community-acquired pneumonia (CAP) is a leading cause of morbidity and mortality worldwide. It is the third leading cause of death in the world and the fourth leading cause of death in developing countries [1]. CAP is one of the most common infectious diseases needing hospitalization.

The reported incidence rate of CAP in India is 4 million cases per year [2]. India accounts for $23 \%$ of the global pneumonia burden and $36 \%$ of the WHO regional burden $[2,3]$. The clinical presentation of CAP is variable and because of the wide spectrum of associated clinical features, CAP is a part of the differential diagnosis of nearly all respiratory illnesses [3].

The presentation of CAP may range from mild pneumonia characterized only by fever and productive cough to severe fulminant pneumonia leading to respiratory distress and sepsis syndrome requiring management in ICU. Any delay in ICU admission has been shown to be associated with increased mortality $[1,2,3]$.

Also, unnecessary admission to ICU increases the treatment cost and leads to depletion of precious hospital resources. It is therefore important for physicians to identify patients at low risk of complications who are suitable for outpatient management [4].

Multiple serum biomarkers and several established risk scores such as CURB 65, CRB 65, Pneumonia Severity Index (PSI), Infectious Diseases Society of America/American Thoracic Society (IDSA/ATS) score and Extended CURB 65 have been used to assess the severity of CAP to optimize the management of CAP patients [5]. Out of these scoring systems, PSI and CURB-65 have been most extensively used.

Table-1: Psi Scoring System.

\begin{tabular}{|l|l|}
\hline \multicolumn{2}{|c|}{ Step 1 : Stratify to Risk Class I vs. Risk Classes II-V } \\
\hline Presence of: & Yes/No \\
\hline Over 50 years of age & Yes/No \\
\hline Altered mental status & Yes/No \\
\hline Pulse $\geq 125 /$ minute & Yes/No \\
\hline Respiratory rate $>30 /$ minute & Yes/No \\
\hline Systolic blood pressure $<90 \mathrm{mmHg}$ & Yes/No \\
\hline Temperature $<350 \mathrm{C}$ or $>400 \mathrm{C}$ & \\
\hline History of & Yes/No \\
\hline Neoplastic disease & Yes/No \\
\hline Congestive heart disease & \\
\hline
\end{tabular}

\begin{tabular}{|c|c|}
\hline Cerebrovascular disease & Yes/No \\
\hline Renal disease & Yes/No \\
\hline Liver disease & Yes/No \\
\hline \multicolumn{2}{|l|}{ If any "Yes", then proceed to step 2} \\
\hline \multicolumn{2}{|l|}{ If all "No" then assign to Risk class I } \\
\hline \multicolumn{2}{|l|}{ Step 2: Stratify to Risk class II vs. III vs. IV vs. V } \\
\hline Demographics & Point assigned \\
\hline If Male & +Age (year) \\
\hline If Female & + Age(year)-10 \\
\hline Nursing home resident & +10 \\
\hline \multicolumn{2}{|l|}{ Comorbidity } \\
\hline Neoplastic disease & +30 \\
\hline Liver disease & +20 \\
\hline Congestive heart disease & +10 \\
\hline Cerebrovascular disease & +10 \\
\hline Renal disease & +10 \\
\hline \multicolumn{2}{|l|}{ Physical Exam Findings } \\
\hline Altered mental status & +20 \\
\hline Pulse $\geq 125 /$ minute & +20 \\
\hline Respiratory rate $>30 /$ minute & +20 \\
\hline Systolic blood pressure $<90 \mathrm{mmHg}$ & +15 \\
\hline Temperature $<350 \mathrm{C}$ or $>40 \circ \mathrm{C}$ & +10 \\
\hline \multicolumn{2}{|l|}{ Lab and Radiographic Findings } \\
\hline Arterial pH $<7.35$ & +30 \\
\hline Blood Urea Nitrogen $\geq 30 \mathrm{mg} / \mathrm{dl}$ ( $9 \mathrm{mmol} / \mathrm{liter})$ & +20 \\
\hline Sodium $<130 \mathrm{mmol} /$ liter & +20 \\
\hline Glucose $\geq 250 \mathrm{mg} / \mathrm{dl}$ & +10 \\
\hline Hematocrit $<30 \%$ & +10 \\
\hline Partial pressure of arterial $02<60 \mathrm{~mm} / \mathrm{Hg}$ & +10 \\
\hline Pleural effusion & +10 \\
\hline \multicolumn{2}{|l|}{$<70=$ Risk Class II } \\
\hline \multicolumn{2}{|l|}{$71-90=$ Risk Class III } \\
\hline \multicolumn{2}{|l|}{ 91-130 = Risk Class IV } \\
\hline$>130=$ Risk Class $\mathrm{V}$ & \\
\hline
\end{tabular}

Table-2: Curb 65 scoring system.

\begin{tabular}{|l|l|l|}
\hline \multicolumn{1}{|c|}{ Symptoms } & Points \\
\hline$C$ & Confusion & 1 \\
\hline$U$ & Urea $\geq 19 \mathrm{mg} / \mathrm{dl}$ & 1 \\
\hline$R$ & Respiratory rate of $\geq 30$ breaths $/ \mathrm{min}$ & 1 \\
\hline$B$ & SBP $\leq 90 \mathrm{mmHg}$ or DBP $\leq 60 \mathrm{mmHg}$ & 1 \\
\hline Age & $\geq 65$ years & 1 \\
\hline CURB 65 Classification & \multicolumn{2}{|l|}{} \\
\hline CURB 65 Class & Score \\
\hline 1 & $0-1$ \\
\hline 2 & 2 \\
\hline 3 & 3 \\
\hline 4 & $4-5$ \\
\hline
\end{tabular}

PSI was developed by Fine et al in the Universityf Pittsburgh, the USA in 1997 to identify low-risk patients of CAP. The PSI assigns points based on 
Age, presence of coexisting disease, abnormal physical findings, and abnormal laboratory findings (such as a pH $<7.35$, a blood urea nitrogen concentration $\geq 30 \mathrm{mg}$ per deciliter $[11 \mathrm{mmol}$ per liter] or a sodium concentration $\leq 130 \mathrm{mmol}$ per liter) at presentation. The patients are stratified into five groups based on a total score (Table 1) [6].

CURB- 65 was developed by Lim et alt the University of Nottingham, the UK in 2002for predicting mortality in cases of CAP. The score is an acronym for each of the risk factors measured: new-onset Confusion, Blood Urea nitrogen greater than $7 \mathrm{mmol} / \mathrm{l}(19 \mathrm{mg} / \mathrm{dl})$, Respiratory rate of $\geq 30$ breaths per minute, Blood pressure $\leq 90 \mathrm{mmHg}$ systolic or diastolic blood pressure $\leq 60 \mathrm{mmHg}$ and age 65 or older [7]. Each risk factor scores one point, for a maximum score of 5 (Table 2). CURB-65 is easier to remember and simpler to calculate in clinical practice.

CURB 65 and PSIscoring systems have not been validated in developing countries where population demographics and health-care delivery systems are totally different from the developed world [8]. To date, only a few studies have been conducted in India comparing various prognostic scores. This study was conducted to compare PSI and CURB-65 scores in an Indian context and compared the two scoring systems.

\section{Aim}

The present observational study was aimed to compare the sensitivity and specificity of CURB-65 and PSI scoring systemsin predicting ICU admission and mortality in cases of CAP.

\section{Material and Methods}

Thisobservational study was conducted in a tertiary care teaching hospital in western Maharashtra from August 2018 for a period of six months after due approval from the institutional ethical committee and scientific committee. One hundred consecutiveconsentingCAP patients admitted to the hospital were included in the study.

Inclusion criteria: Allconsenting patients of $\geq 18$ years of age reporting with clinical features and laboratory/radiological evidence of pneumonia, were included in the study.

Exclusion criteria: All cases where clinical and/or radiological findings could be explained by any respiratory pathology other than CAP were excluded
From the study. Immunosuppressed patients (HIV patients, solid organ transplant, post-splenectomy on steroids or chemotherapy) and those withhospital-acquired or healthcare-associated pneumonia were also excluded from the study.

\section{Methodology}

A detailed preapproved proforma was filled up for each patient including history, clinical findings, routine blood investigations, chest x-ray, sputum for Gram stain, culture and antibiotic sensitivity pattern, sputum AFB, bloodculture and other investigations on as required basis. CURB-65 and PSI scores were calculated for each patient and they were categorized as per score at the time of admission.

All patients were reassessed daily clinically and radiographically for improvement or development of complications. Treatment of the patients including the decision for ICU admission, mechanical ventilation, and inotropic/vasopressor support was by the treating physician who was blinded to the prognostic score of the patient.

Statistical Analysis: A $x^{2}$ statistics test (with Yates correction when applicable) was used to evaluate the statistical significance of categorical variables. The results were presented as mean (SD). Odds ratios with $95 \%$ confidence intervals were computed using a univariate logistic regression model with ICU outcome as the dependent variable. Using Epi Info 1.4.3 all statistical tests were 2-tailed and a P-value $<0.05$ was considered significant.

Observations: The present study included one hundred cases of CAP; the mean age of patients was $54.33 \pm 16.87$ years, ranging from 18 to 90 in males and 18 to 82 in females. Twenty-nine percent of patients were aged more than 65 years. Males (64\%) were affected more than females (36\%) almost in the ratio of $2: 1$. Twenty-five patients had more than one co-morbid condition. Eighteen patients expired during the hospital stay.

\section{Analysis of scoring systems}

ICU Admissions: In the present study, 24 patients out of 100 cases with CAP required ICU admission. Table 3 shows patients of various PSI classes who required ICU admission and the majority of them belonged to class IV and V. PSI Class IV hadnine (26.47\%) admissions with sensitivity and specificity of $77.52 \%$ and $88.46 \%$ respectively.

As the severity of CAP increased, the number of ICU 
Admissions increased; with PSI class Vshowingthe highest number of admissions, ten out of 14 patients (71.42\%) with sensitivity and specificity of $84.16 \%$ and $91.58 \%$ respectively. CURB 65 III and IV had a sensitivity of $40.84 \%$ and $38.84 \%$ and specificity $69.48 \%$ and $72.08 \%$ respectively for ICU admissions (Table 4).

The PSI class $\geq$ IV was found to have higher sensitivity and specificity in predicting ICU admission than CURB-65 class $\geq$ III. Positive Predictive Value (PPV) for ICU admission was highest for PSI class IV and $V$ (67.24\% and $69.40 \%$ ) as compared to CURB 65 class III and IV (48.42\% and 60.52).

The Negative Predictive Value (NPV) for ICU admission in PSI class IV and $V(77.61 \%$ and 82.24\%) was higherasompared to CURB 65 III and IV (68.17\% and 78.26\%). Both PPV and NPV werefound better for PSI class $\geq$ IV than CURB 65 class $\geq$ III.

Table-3: Sensitivity, specificity, NPV, and PPV for different PSI classes in predicting ICU admissions.

\begin{tabular}{|l|l|l|l|l|l|}
\hline \multirow{2}{*}{ Variables } & \multicolumn{5}{c|}{ PSI Classes } \\
\cline { 2 - 7 } & Class 1 & Class 2 & Class 3 & Class 4 & Class 5 \\
\hline Total cases & 12 & 21 & 19 & 34 & 14 \\
\hline $\begin{array}{l}\text { ICU Admission (\%) Total -24 } \\
\text { patients }\end{array}$ & $0(0 \%)$ & 2 & 3 & 9 & 10 \\
& & $(9.52 \%$ & $(15.79 \%$ & $(26.47 \%$ & $(71.42 \%)$ \\
\hline Sensitivity (\%) & & 64.21 & 68.24 & 77.52 & 84.16 \\
\hline Specificity (\%) & 84.86 & 84.54 & 82.34 & 88.46 & 91.58 \\
\hline PPV (\%) & & 68.52 & 54.42 & 67.24 & 69.40 \\
\hline NPV (\%) & 76.81 & 76.48 & 74.98 & 77.61 & 82.24 \\
\hline P value & 0.042 & 0.026 & 0.035 & 0.019 & 0.0001 \\
\hline
\end{tabular}

Table-4: Sensitivity, specificity, NPV, and PPV for different CURB 65 classes in predicting ICU admissions.

\begin{tabular}{|l|l|l|l|l|}
\hline \multirow{2}{*}{ Variables } & \multicolumn{4}{|c|}{ CURB 65 Classes } \\
\cline { 2 - 5 } & Class 1 & Class 2 & Class 3 & Class4 \\
\hline Total cases & 37 & 33 & 24 & 6 \\
\hline $\begin{array}{l}\text { ICU Admission (\%) Total -24 } \\
\text { patients }\end{array}$ & 1 & 6 & 13 & 4 \\
\hline Sensitivity (\%) & $(2.70 \%)$ & $(18.18 \%)$ & $(54.17 \%)$ & $(66.7 \%)$ \\
\hline Specificity (\%) & 12.68 & 38.47 & 40.84 & 38.84 \\
\hline PPV (\%) & 40.26 & 52.16 & 69.48 & 72.08 \\
\hline NPV (\%) & 12.35 & 24.52 & 48.42 & 60.52 \\
\hline P value & 24.27 & 58.42 & 68.17 & 78.26 \\
\hline
\end{tabular}

Table-5: Sensitivity, Specificity, NPV, and PPV for different CURB 65 classes in predicting mortality.

\begin{tabular}{|l|l|l|l|l|}
\hline \multirow{2}{*}{ Variables } & \multicolumn{4}{c|}{ CURB 65 Classes } \\
\cline { 2 - 5 } & Class 1 & Class 2 & Class 3 & Class 4 \\
\hline Total cases & 37 & 33 & 24 & 6 \\
\hline $\begin{array}{l}\text { Mortality (\%) Total-18 } \\
\text { patients }\end{array}$ & $0(0 \%)$ & 4 & 10 & 4 \\
\hline Sensitivity (\%) & & $(12.12 \%)$ & $(41.66 \%)$ & $(66.66 \%)$ \\
\hline Specificity (\%) & - & 74.58 & 86.59 & 89.64 \\
\hline PPV (\%) & 62.42 & 82.43 & 89.64 & 97.54 \\
\hline NPV (\%) & - & 76.42 & 79.56 & 90.60 \\
\hline P value & 65.54 & 74.62 & 92.56 & 95.24 \\
\hline
\end{tabular}

Table-6: Sensitivity, Specificity, NPV, and PPV for different PSI classes in predicting mortality.

\begin{tabular}{|l|l|l|l|l|l|}
\hline \multirow{2}{*}{ Variables } & \multicolumn{5}{|c|}{ PSI Classes } \\
\cline { 2 - 6 } & Class 1 & Class 2 & Class 3 & Class 4 & Class 5 \\
\hline Total cases & 12 & 21 & 19 & 34 & 14 \\
\hline $\begin{array}{l}\text { Mortality (\%) Total } \\
-18\end{array}$ & $0(0 \%)$ & 1 & 2 & 6 & 9 \\
\hline Sensitivity (\%) & 68.52 & 57.82 & 64.58 & 68.92 & 72.58 \\
\hline Specificity (\%) & - & 6.21 & 16.53 & 24.74 & 54.86 \\
\hline PPV (\%) & - & 9.42 & 14.59 & 12.48 & 58.24 \\
\hline NPV (\%) & 64.38 & 55.32 & 60.27 & 58.62 & 74.86 \\
\hline P value & 0.362 & 0.425 & 0.04 & 0.002 & 0.0001 \\
\hline
\end{tabular}

Mortality: Analysis of CURB 65revealed that mortality was zero in class I of 37 patients, class II four $(12.12 \%)$ of 33 patients, class III was ten $(41.66 \%)$ of 24 patients and IV was four $(66.66 \%)$ of six patients. The sensitivity of CURB 65 was $86.59 \%$ in class III and $89.64 \%$ in class IV, That of Specificity in class III and IV was $89.64 \%$ and 97.54\% respectively.

In PSI scoring system, there was no mortality out of 12 patients in class I, $4.7 \%$ of 21 patients in class II, $10.53 \%$ of 19 patients in class III, $17.65 \%$ of 34 patients in class IV and highest (64.29\%) of 14 patients in class V. Sensitivity and specificity of class IV and $\mathrm{V}$ of PSI scoring system to predict death increased from $68.92 \%$ to $72.58 \%$ and $24.74 \%$ to $54.86 \%$ respectively.

There was a statistically significant difference $(P<$ 0.005 ) when the sensitivity and specificity of scoring systems were compared. CURB 65 has higher sensitivity and specificity than PSI in predicting mortality in CAP. PPVfor mortality was higher for CURB 65 class III and IV (79.56\% and 90.60\%) as compared to PSI class IV and V (12.48\%, 58.24\%).

NPVfor mortality was higher for CURB 65 III and IV (92.56\% and $95.24 \%$ ) as compared to PSI class IV and $V(58.62 \%$ and $74.86 \%)$. Both PPV and NPV werea better predictor of mortality for CURB 65 
Class $\geq$ III than PSI class $\geq$ IV.

\section{Discussion}

In cases of CAP,the majority of admissions to the ICU occur within the first $24 \mathrm{~h}$ of illness. Delayed transfer to the ICU is associated with increased mortality, and therefore early recognition of these patients is important. The mean age in the present study was $54.33 \pm 16.87$ (38 to 71 ).

Mean age in studiesby Babu et al and Dey et al was $53( \pm 17)$ years and 50.6 years respectively $[10,11]$. In the present study, the incidence of pneumonia increased with age; this finding was consistent with the study by Mohanty $S$ et al [9].

Study included 100 cases of CAP, of which twentyfour $(24 \%)$ of patients required ICU admission, sixteen $(16 \%)$ needednvasive ventilatory support, and two patients required non-invasive Ventilation. Fifteen patients (15\%) needed inotropic support. In the present study, the majority of patients admitted in ICU were from PSI class IV and V and CURB 65 class III and IV.

Nine $(26.47 \%)$ out of 34 patients of PSI class IV, and $10(71.42 \%)$ out of 14 patients of PSI class $V$, were admitted in ICU. Similarly, $13(54.17 \%)$ out of 24 cases of CURB 65 class III, and four $(66.7 \%)$ out of six patients of CURB 65 class IV, were admitted in ICU.

This was similar to study by Shah et al and Mohanty $S$ et alin which ICU admissions were $23.33 \%$ and $25 \%[5,9$,$] As the severity class of the scoring$ system increased, the percentage of ICU admission also increased. In the Study by Madhu S et al, ICU admission was $24 \%$ almost similar to the current study [12].

In the present study, the overallortality was $18 \%$. Ina study by Mohanty $S$ et al, Dey et al and Shah et almortality was $13.28 \%, 25.38 \%$, and $10.7 \%$ respectively $[5,9,11]$. The mortality increased as the PSI and CURB 65 severity increased. This finding is similar to that found by Shah BA et al which showed a linear rise in mortality with severity of CAP in both CURB 65 and PSI scoring systems [8].

However, Madhu et al, in their study found that overall mortality was $18 \%$ and, the mortality rate and need for ICU admission increased progressively with increasing scores of PSI but the CURB-65 score did not show this correlation [12].

Mortality was $49.4 \%$ in the study by Woodhead et
$\mathrm{Al}$; this apparently higher mortality was probably due to delayed admission of the patients into ICU [4]. In the current study alsohigher mortality was found in those admitted late to ICU. Overall, CURB 65 had better sensitivity and specificity than PSI in predicting mortality in CAP patients. These results are comparable withthe study by Shah BA et al [8].

The two scoring systems, PSI and CURB-65 are complementary to each other in predicting ICU admission and mortality. The PSI was developed to identify low mortality risk patients, but this scoring system can occasionally underestimate the severity of illness, especially in young patients without comorbid illnesses [6].

This is because the PSI relies more on age and comorbidities, and therefore, the young patients without any comorbidities may be placed in a lower PSI class and may not receive the care they actually required. In contrast, the CURB-65 approach may be ideal for identifying high mortality risk patients with severe illness due to CAP.

However, one clear shortfall of the CURB-65 approach is that it does not account for comorbid illness, and thus may not be realistic in older patients who may have considerable mortality risk even with low CURB-65 score. Even a mild form of CAP may destabilize a chronic, but compensated disease process.

Both the prognostic systems offer a valuable assessment of patient illness, but from different perspectives, and are therefore complementary to each other at identifying low risk and high-risk CAP patients [6].

\section{Conclusion}

In this study, an attempt has been made to compare the prognostic capability of the two commonly used scoring systems for assessing severity in cases of CAP. The study has its limitation in that the patients with comorbidities like malignancy, chemotherapy, and steroid therapy were excluded from the study and therefore PSI score may not have been a true reflection of the severity of CAP cases in the community.

\section{What does the study add to the existing knowledge}

In the current study, PSI was found to be better in the predictor of the need for ICU admission; 
The CURB 65 was found to be a better predictor of mortality.By applying the knowledge of these two scoring systems, patients of CAP can be better prognosticated regarding the severity of their illness and the need for intensive monitoring.More realistic triaging of patients will ultimately result in providing appropriate timely interventionforoptimalutilization of hospital resources and favorable outcomes.

\section{Author's contribution}

Dr. Prashant Patil: Collection of data and patient management

Dr. Arun Tyagi: Overall supervision, preparation of the final article and corresponding author

Dr. Manoj Waghmare: Faculty in-charge pulmonology, overall supervision of patient management

Dr. A.K. Srivastava: Preparation of the manuscript Dr. Marcia Waran: Proofreading

\section{Reference}

01. Regional situation on health statistics reporting. Health Situation in the South-East Asia Region 201-2007. New Delhi- EHI/WHO-SEARO. 2007. Available at: [Article] [Crossref]

02. Farooqui $H$, Jit $M$, Heymann DL, Zodpey $S$. Burden of severe pneumonia, pneumococcal pneumonia and pneumonia deaths in Indian states- Modelling based estimates. PLoS One. 2015;10(6)e0129191 doi: [Article] [Crossref]

03. Prasad P, Bhat S. Clinico microbiological study of community acquired pneumonia. Lung India. 2017;34(5)491-492. doi: [Article] [Crossref]

04. Woodhead MA, Welch CA, Harrison DA, Bellingan G, Ayres JG. Community-acquired pneumonia on the intensive care unitsecondary analysis of 17,869 cases in the ICNARC case mix programme data base. Crit Care. $2006 ; 10(2) S 1$.

doi: [Article] [Crossref]

05. Fine $M J$, Auble TE, Yealy DM, Hanusa $B H$, Weissfeld LA, Singer DE, et al. A prediction rule to identify low risk patients with community acquired pneumonia. $\mathrm{N}$ Engl J Med. 1997;336(4)243250.

doi: [Article] [Crossref]
06. Shah BA, Ahmed W, Dhobi GN, Shah NN, Khursheed SQ, Haq I. Validity of pneumonia severity index and CURB 65 severity scoring systems in community acquired pneumonia in an Indian setting. Indian J Chest Dis Allied Sci. 2010;52(1)9 17.

[Crossref]

07. Lim WS, Baudouin SV, George RC, Hill AT, Jamieson C, Le Jeune I, et al. BTS guidelines for the management of community acquired pneumonia in adults- update 2009. Thorax. 2009;64(3)iii1-55.

doi: [Article] [Crossref]

08. Shah BA, Singh G, Naik MA, Dhobi GN. Bacteriological and clinical profile of Community acquired pneumonia in hospitalized patients. Lung India. 2010;27(2)54 57. doi: [Article] [Crossref]

09. Mohanty S, Babu VH. comparative study of newer prognostic scoring systems in predicting severity in community acquired pneumonia in hospitalized patients. IOSR-JDMS. 2016;15(6)146-152.

doi: [Article] [Crossref]

10. Akhila Babu, Nybin Jose, Jona J. A Prospective Observational Study to Evaluate the Severity Assessment Scores in Community-acquired Pneumonia for Adult Patient. Indian J Respir Care. 2017;6(2)820-823. doi: [Article] [Crossref]

11. Dey $A B$, Nagarkar KM, Kumar V. Clinical presentation and predictors of outcome in adult patients with community acquired pneumonia. National Med J India. 1997;10(4):169-172. [Crossref]

12. Madhu S, Augustine S,Kumar YSR, Kauser MM, Kumar SRV, Jayaraju BS. Comparative study of CURB-65, Pneumonia Severity Index and IDSA/ATS scoring systems in community acquired pneumonia in an Indian tertiary care setting. Int J Adv Med. 2017;4(3)693-700. doi: [Article] [Crossref] 